\title{
Origin and Early Evolution of Angiosperms
}

\author{
Douglas E. Soltis, ${ }^{a}$ Charles D. Bell, ${ }^{b}$ Sangtae Kim, ${ }^{c}$ \\ and Pamela S. Soltis ${ }^{d}$ \\ ${ }^{a}$ Department of Botany, University of Florida, Gainesville, Florida, USA \\ ${ }^{b}$ Department of Biological Sciences, University of Nerw Orleans, \\ New Orleans, Louisiana, USA \\ ${ }^{c}$ National Institute of Biological Resources, Incheon, Korea \\ ${ }^{d}$ Florida Museum of Natural History, University of Florida, Gainesville, Florida, USA
}

\begin{abstract}
Contributions from paleobotany, phylogenetics, genomics, developmental biology, and developmental genetics have yielded tremendous insight into Darwin's "abominable mystery"- the origin and rapid diversification of the angiosperms. Analyses of morphological and molecular data reveal a revised "anthophyte clade" consisting of the fossils glossopterids, Pentoxylon, Bennettitales, and Caytonia as sister to angiosperms. Molecular estimates of the age of crown group angiosperms have converged on 140180 million years ago $(\mathrm{Ma})$, older than the oldest fossils (132 Ma), suggesting that older fossils remain to be discovered. Whether the first angiosperms were forest shrubs (darkand-disturbed hypothesis) or aquatic herbs (wet-and-wild hypothesis) remains unclear. The near-basal phylogenetic position of Nymphaeales (water lilies), which may include the well-known fossil Archaefructus, certainly indicates that the aquatic habit arose early. After initial, early "experiments," angiosperms radiated rapidly ( $\leq 5$ million years [Myr]), yielding the five lineages of Mesangiospermae (magnoliids and Chloranthaceae as sisters to a clade of monocots and eudicots + Geratophyllaceae). This radiation ultimately produced approximately $97 \%$ of all angiosperm species. Updated estimates of divergence times across the angiosperms conducted using nonparametric rate smoothing, with one or multiple fossils, were older than previous reports, whereas estimates using PATHd8 were typically younger. Virtually all angiosperm genomes show evidence of whole-genome duplication, indicating that polyploidy may have been an important catalyst in angiosperm evolution. Although the flower is the central feature of the angiosperms, its origin and subsequent diversification remain major questions. Variation in spatial expression of floral regulators may control major differences in floral morphology between basal angiosperms and eudicot models.
\end{abstract}

Key words: phylogeny; divergence; floral evolution; genome evolution

\section{Introduction}

Angiosperms represent one of the greatest terrestrial radiations. The oldest fossils date from the early Cretaceous (Friis et al. 2006), 130-136 million years ago (Ma), followed by a rise to ecological dominance in many habitats before the end of the Cretaceous. Darwin referred to the origin of the angiosperms

Address for correspondence: Douglas E. Soltis, Department of Botany, University of Florida, Gainesville, FL 32611.dsoltis@botany.ufl.edu as "an abominable mystery" in a well-known quotation taken from a letter to J.D. Hooker. Through contributions from paleobotany, phylogenetics, classical developmental biology, and modern developmental genetics (evo-devo), tremendous progress has recently been made in elucidating the origin and diversification of the angiosperms. We attempt to synthesize and summarize many of these recent developments, noting their importance to the rapidly changing angiosperm paradigm. We also provide a possible road map for future research. 


\section{Fossils}

Paleobotany has at least three crucial roles to play in resolving the origin and early diversification of the flowering plants and addressing the following questions: (1) What lineage is ancestral to the angiosperms? (2) What were the first angiosperms, and how have characters evolved? Fossil discoveries and the analysis of existing data have made significant contributions to our understanding of the possible ancestors of flowering plants (see most recently Friis et al. 2007), as well as to the early diversification of angiosperms. (3) When did the major clades of angiosperms diversify, on the basis of fossil calibrations and molecular-based methods?

\section{Ancestors of Flowering Plants}

The closest relatives of angiosperms remain a mystery. Phylogenetic analysis of morphological features conducted in the 1980s suggested that Gnetales were the closest living relatives of angiosperms (e.g., Crane 1985; Doyle \& Donoghue 1986). Cladistic analyses of extant and fossil taxa recovered a clade of Bennettitales, Pentoxylon, Gnetales, and angiosperms (Crane 1985; Doyle \& Donoghue 1986). Doyle and Donoghue (1986) named this clade the "anthophytes" in reference to the flowerlike reproductive structures in all members. The anthophyte hypothesis, that angiosperms belong to this clade and are possibly sister to the gnetophytes, concomitantly had a profound effect on views of the evolution of the angiosperms. For example, acceptance of the anthophyte hypothesis stimulated the reinterpretation of character evolution (Frohlich 1999; Donoghue \& Doyle 2000), including the origin of the carpel and double fertilization (Friedman 1994; Doyle 1998).

Molecular phylogenetic studies, however, later revealed that Gnetales are not the sister group to the angiosperms but that extant gymnosperms form a clade, with Gnetales most likely associated with conifers (e.g., Qiu et al.
1999; Soltis et al. 1999a; Chaw et al. 2000; Magallón \& Sanderson 2002; Burleigh \& Mathews 2004). Furthermore, there are no known fossils representing unequivocal stem group angiosperms (i.e., angiosperms that clearly attach below the basal node leading to Amborella, Nymphaeales, and all other living angiosperms). Hence, determining the closest relatives of angiosperms is a major challenge.

The demise of the anthophyte hypothesis profoundly altered views of angiosperm origins; accompanying this demise is a need for alternatives. If no extant gymnosperm is sister to angiosperms, what fossil lineages, if any, are closely related to flowering plants? Doyle (2001) and Soltis et al. (2005) conducted a series of analyses of morphological and molecular data sets involving extant taxa, as well as fossils, to reassess the closest relatives of the angiosperms. These analyses yielded similar results and revealed a revised "anthophyte clade." In this clade Caytonia is sister to angiosperms, followed by Bennettitales, Pentoxylon, and glossopterids (Fig. 1). Hence, fossils such as Caytonia and Bennettitales may be the closest relatives of angiosperms (Fig. 1). However, the recent discovery that gnetophytes and Bennettitales share features (Friis et al. 2007) suggests that further attention be given to circumscribing and evaluating a revised anthophyte clade. Although these analyses are useful, one of the biggest remaining challenges facing evolutionary biologists is ascertaining the fossil lineages that represent the closest relatives of angiosperms. Do Caytoniales and Bennettitales actually represent these lineages? Are there key fossil links that remain to be discovered?

\section{The Earliest Angiosperms: Fossils}

There are two highly divergent views on the general habit of the earliest angiosperms: woody and terrestrial or herbaceous and aquatic. This has actually been a longstanding debate (reviewed in Soltis et al. 2005). The hypothesis that the earliest angiosperms were woody is supported by the fact that most basal 

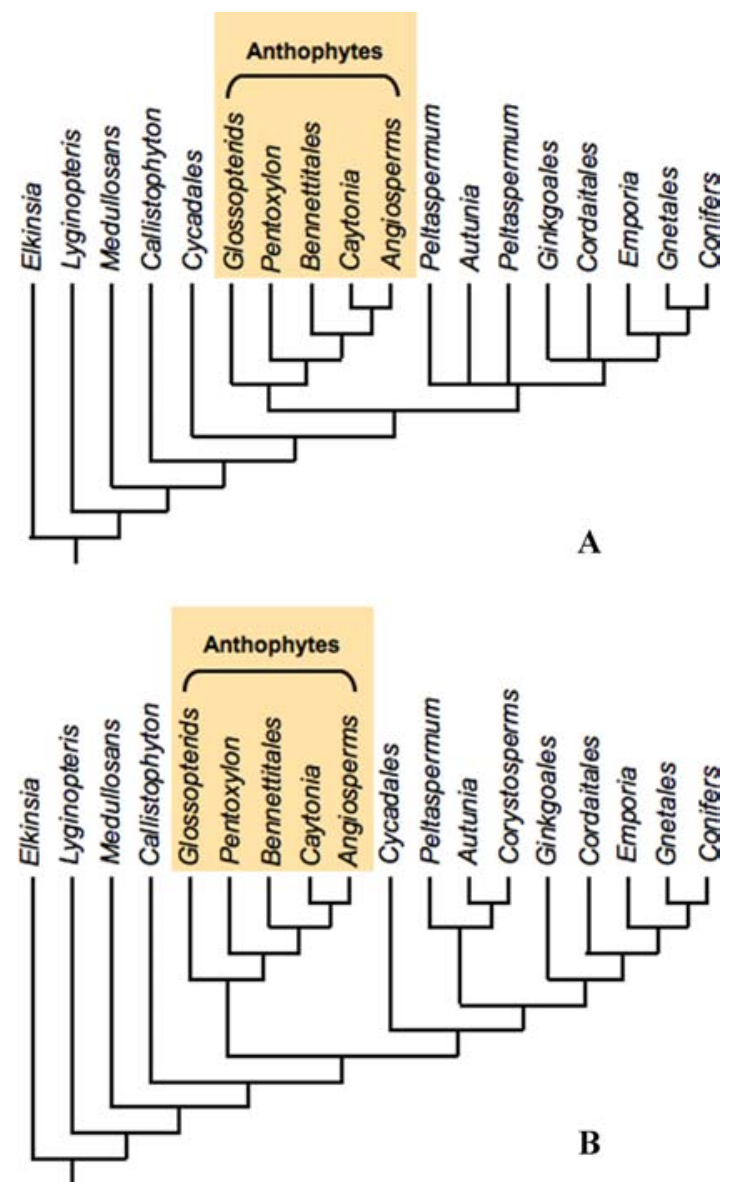

Figure 1. Revised views of the phylogeny of seed plants showing putative closest relatives of angiosperms obtained by using both the morphological matrix of Doyle (1996) and molecular data (reviewed in Soltis et al. 2005). A revised "anthophyte" clade is depicted. (A) Tree modified from Soltis et al. (2005), in which molecular data for seed plants are combined with the morphological matrix of Doyle (1996). (B) Tree modified from Doyle (2001), in which a molecular constraint is used, placing Gnetales with other extant gymnosperms.

angiosperms are woody, and all gymnosperms are woody, as are the fossil lineages that are considered most closely related to angiosperms (e.g., Caytoniales, Bennettitales; see earlier discussion). Amborella, the sister to all other living angiosperms, is woody, as are members of Austrobaileyales, another early-branching lineage of living angiosperms.

An aquatic origin of angiosperms is supported by the fact that several of the earliest known fossil angiosperms were aquatic. Archaefructus represents perhaps the oldest, most complete angiosperm fossil (Sun et al. 2002); it is estimated to be approximately 115-125 million years (Myr) old. On the basis of morphology, it clearly was aquatic. The phylogenetic placement of the fossil Archaefructus as sister to all extant angiosperms (Sun et al. 2002), plus the near-basal phylogenetic position of extant Nymphaeales (water lilies, below), lends support to the view that the aquatic habit arose early in angiosperms and that perhaps the earliest angiosperms were aquatic. However, later analyses (e.g., Friis et al. 2003) questioned the placement of Archaefructus as sister to all extant angiosperms; some analyses of Friis et al. placed Archaefructus with water lilies. The recent discovery that Hydatellaceae are part of the water lily clade (Saarela et al. 2007), and hence a new branch near the base of the angiosperms, greatly increases the morphological diversity encompassed by the Nymphaeales clade. This finding raised the possibility that Nymphaeales were once much more diverse, and could have encompassed Archaefructus, as well as other now-extinct lineages (Doyle, submitted). Hence, it now seems prudent to keep an open mind regarding the placement of $A r$ chaefructus - it represents well the difficulty in placing fossil lineages that are morphologically distinct, with no clear synapomorphies with extant taxa.

Another early angiosperm fossil (unnamed) was considered a possible water lily relative by Friis et al. (2001). This fossil is dated at approximately 125-115 Myr old and was used as evidence to support the antiquity of the Nymphaeales lineage. This putative ancient water lily fossil is therefore extremely important in discussions of the diversification of Nymphaeales, as well as the angiosperms. A phylogenetic analysis, using the morphological data set of Les et al. (1999) for extant Nymphaeales, placed the fossil as sister to Nymphaeales; synapomorphies with extant Nymphaeales included a syncarpous gynoecium, a perigynous or epigynous perianth, and 
a central protrusion of the floral apex between the carpels. However, neither of the last two characters is found consistently throughout Nymphaeales (Friis et al. 2001). The unnamed fossil exhibits features shared by both Nymphaeales and Illicium (Austrobaileyales) (Friis et al. 2001; Gandolfo et al. 2004; Yoo et al. 2005) and occurs in a site with abundant fossil seeds attributed to Illiciales (Friis et al. 2001). The recent molecular analyses and dating experiments of Yoo et al. (2005) raise the possibility that the unnamed fossil of Friis et al. may have actually been part of an ancient assemblage that included Nymphaeales and Austrobaileyales. That is, the unnamed fossil probably occupies a deeper place on the angiosperm tree than the branch leading to water lilies. Endress (2008) recently reached the same conclusion on the basis of a reexamination of the morphology of Microvictoria (Gandolfo et al. 2004) - the fossil differs in key features from extant genera of Nymphaeaceae.

This unnamed fossil of Friis et al. (2001) and Archaefructus certainly indicate that the aquatic habit arose early in angiosperm evolution. This view is further supported by the near-basal placement of Nymphaeales (water lilies) in phylogenies of extant taxa. However, there are undoubtedly earlier, as yet undiscovered, angiosperm fossils. In this regard, molecular estimates for the age of the angiosperms are converging; most recent estimates are in the range of 140-180 Ma (Bell et al. 2005), suggesting an age for flowering plants that is substantially older than the date of $132 \mathrm{Ma}$ on the basis of the known fossil record. These molecular estimates suggest, in fact, that the earliest angiosperms may have arisen in the late Jurassic, rather than the early Cretaceous, and that the oldest angiosperm fossils are still undiscovered.

\section{Phylogenetics}

\section{Resolving the Big Picture}

One of most exciting recent developments in the study of angiosperm evolution has been the enormous progress made in elucidating angiosperm evolutionary history (reviewed in Judd \& Olmstead 2004; Soltis \& Soltis 2004; Soltis et al. 2005). We provide a summary tree of our current understanding of angiosperm relationships (Fig. 2). Phylogenetic analyses based on an ever-increasing number of gene sequences have clearly and unequivocally established the first branches of extant angiosperm diversity. Many studies have revealed strong support for the sister relationship of Amborellaceae, followed by Nymphaeales, and then Austrobaileyales to all other extant angiosperms (Mathews \& Donoghue 1999, 2000; Parkinson et al. 1999; Qiu et al. 1999, 2000, 2005; Soltis et al. 1999b, 2000, 2004; Barkman et al. 2000; Graham \& Olmstead 2000; Graham et al. 2000; Soltis et al. 2000; Zanis et al. 2002,2003; Borsch et al. 2003; Hilu et al. 2003; Kim et al. 2004; Stefanović et al. 2004; Leebens-Mack et al. 2005; Stefanović et al. 2005; Jansen et al. 2007; Moore et al. 2007). In most analyses, the monotypic Amborella is followed by the water lilies or Nymphaeales (which comprise Nymphaeaceae) and Cabombaceae (APG II 2003) and Hydatellaceae (Saarela et al. 2007); although a few investigations placed Amborellaceae plus Nymphaeales as sister to all other angiosperms (reviewed in Soltis et al. 2005), recent analyses involving complete or nearly complete plastid genome sequences have placed Amborella alone as sister to all other extant angiosperms (e.g., Jansen et al. 2007; Moore et al. 2007). Although this now appears to be the favored topology, it should be confirmed using nuclear sequence data.

An exciting recent molecular finding is the placement of Hydatella (Hydatellaceae) in the Nymphaeales clade (Saarela et al. 2007). Hydatellaceae had been placed in the monocots (Poales), but molecular data revealed instead that the family is part of the early-diverging angiosperm clade Nymphaeales with high support values. Hence, this is a dramatic phylogenetic shift. This result is important in that it greatly expands the morphological diversity encompassed by the Nymphaeales. For example, 


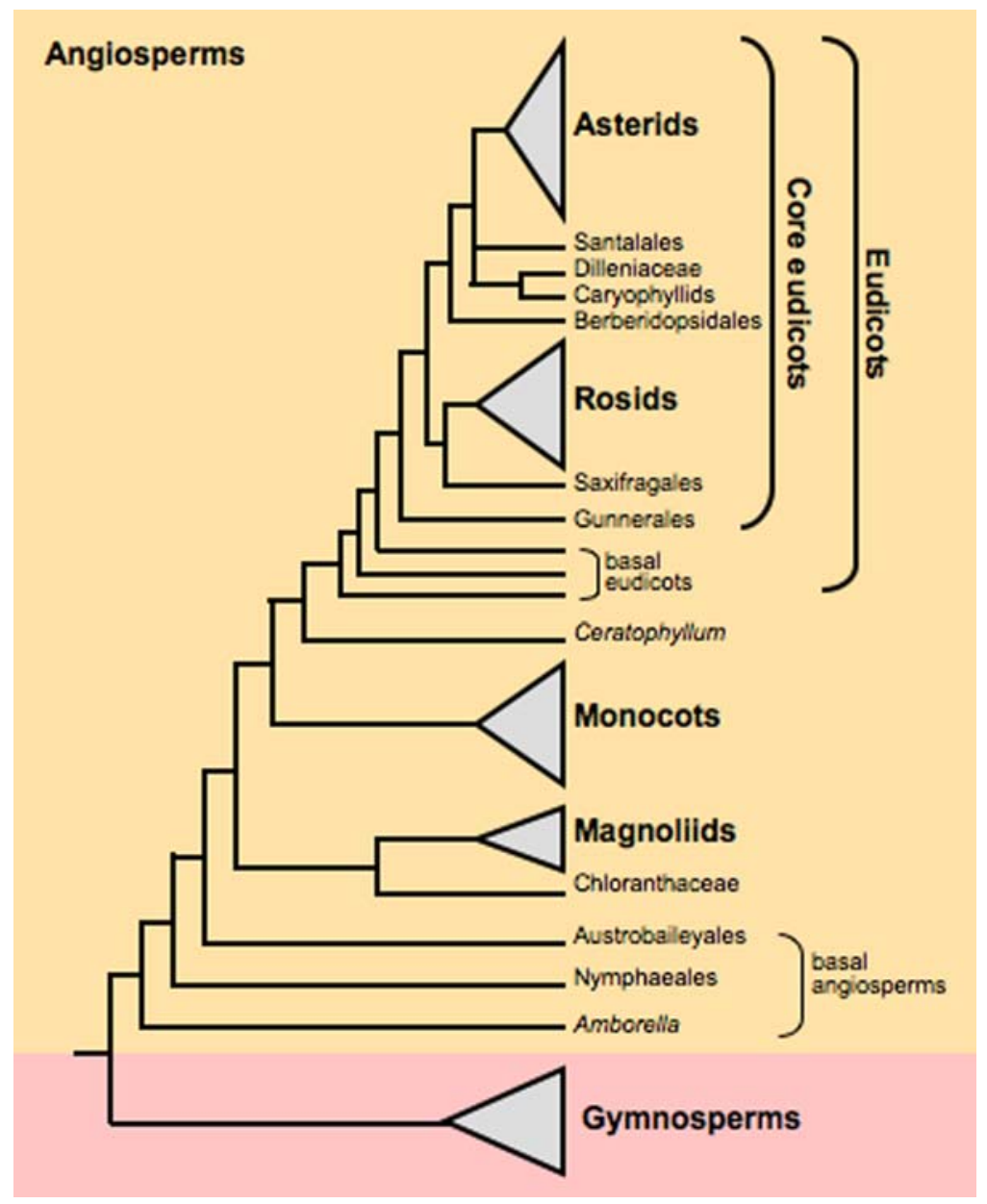

Figure 2. Summary topology of current view of deep-level angiosperm relationships. This topology is based on the analyses of the three-gene, 567-taxon data set (Soltis et al. 2000, 2007 a) with modifications based on the recent analyses of nearly complete plastid genome data sets (Jansen et al. 2007; Moore et al. 2007).

Rudall et al. (2007) proposed that the most plausible interpretation of the reproductive units is that each such unit represents an aggregation of reduced, unisexual, apetalous flowers; this type is different from flowers of Nymphaeales (Rudall et al. 2007). However, Hydatella has ascidiate carpel development, consistent with placement in Nymphaeales. The placement of Hydatella within Nymphaeales raises the possibility that this clade was once far more diverse morphologically and increases the plausibility that the morphology of Archaefructus could be encompassed by this clade, as originally proposed by Friis et al. (2003; see also Doyle, submitted).
After Amborella and Nymphaeales, an Austrobaileyales clade of Illiciaceae, Austrobaileyaceae, and Trimeniaceae is the subsequent sister group to all remaining angiosperms. Whereas these basalmost branches are well supported and resolved, relationships among the remaining major lineages of angiosperms have been unclear and difficult to resolve, with three-, five-, nine-, and even 11-gene data sets (see references above). These remaining angiosperms, or Mesangiospermae (Cantino et al. 2007), are magnoliids, Chloranthaceae, monocots, Ceratophyllaceae, and eudicots. Analyses of multigene data sets with adequate taxon sampling have provided strong support for the 
monophyly of each of these clades of angiosperms. However, different analyses have depicted various relationships among these five clades, with only weak support.

In contrast to earlier studies, recent analyses based on complete or nearly complete plastid genome sequences appear to resolve relationships among these five lineages of Mesangiospermae. After the grade of Amborella, Nymphaeales, and Austrobaileyales, Chloranthaceae and magnoliids may form a clade that is sister to a large clade of monocots and Ceratophyllaceae plus eudicots (Moore et al. 2007) (Fig. 2). The clade of monocots as sister to the eudicot+Ceratophyllum clade is strongly supported (Moore et al. 2007). Jansen et al. (2007) also found these relationships, except that their initial analysis did not include Ceratophyllum. The first three living branches were relatively easy to recover in phylogenetic analyses, a result reported in some of the initial multigene analyses of angiosperms (e.g., Soltis et al. 1999, 2000; Qiu et al. 1999; Parkinson et al. 1999; Mathews \& Donoghue 1999, 2000). These results suggested a more gradual diversification process (or greater extinction) at the base of the angiosperm tree. However, after some initial early "experiments" in angiospermy, the angiosperms rapidly radiated, yielding the five lineages of Mesangiospermae. This is an exciting example of an important molecular insight into Darwin's “abominable mystery." The fossil record certainly supports the presence of many diverse lineages early in angiosperm evolution (e.g., Friis et al. 1994, 1999, 2000, 2001), but phylogenetic analyses of extant angiosperms indicate that the radiation responsible for nearly all extant angiosperm diversity was not associated with the origin of the angiosperms but occurred after the diversification of Amborella, Nymphaeales, and Austrobaileyales (Mathews \& Donoghue 1999; Soltis et al. 1999b). The clades composing the Mesangiospermae (monocots, Ceratophyllaceae, eudicots, Chloranthaceae, and magnoliids) represent the "big bang" of angiosperm evolutionthey diversified rapidly (within only a few mil- lion years); therefore, resolving relationships among these clades has been difficult.

Recent analyses (e.g., Moore et al. 2007; Jansen et al. 2007; Jian et al., 2008) demonstrate that with enough sequence data $(20,000$ or more base pairs), the remaining, problematic, deep-level problems in the flowering plants can also be resolved. Especially promising are analyses involving complete sequencing of the plastid genome (e.g., Jansen et al. 2007; Moore et al. 2007), particularly given the current ease of complete plastid genome sequencing with new sequencing technologies (e.g., Moore et al. 2006). An alternative method that is promising, and much less costly, is the complete sequencing of the slowly evolving inverted repeat of the plastid genome (Jian et al., 2008), which is readily accomplished in most angiosperm groups by using the polymerase chain reaction-based ASAP (amplification, sequencing and annotation of plastomes; Dhingra \& Folta 2005) method.

\section{Implications of Phylogeny for the Earliest Angiosperms}

A well-resolved phylogeny for extant angiosperms has been used as a framework in an effort to reconstruct the habit, as well as other morphological features, of the earliest flowering plants (APG II 2003; Soltis et al. 2005). As noted, Amborella, which is sister to all other extant angiosperms, is woody, as are Austrobaileyales. Anatomical and physiological features of Amborella (which lacks vessel elements) and Austrobaileyales (which have "primitive" vessel elements considered intermediate between tracheids and vessel elements) (Carlquist \& Schneider 2001, 2002) prompted the hypothesis that the earliest angiosperms were understory shrubs, perhaps without vessel elements, and with lower transpiration and stem water movement than is typical of most extant angiosperms (Feild et al. 2000, 2003, 2004). Such plants occupied habitats referred to as "dark and disturbed" and prompted the hypothesis that the first angiosperms were 
understory shrubs living in partially shaded habitats that depended on canopy disturbance to open up new sites for colonization. Outgroup comparisons favor a woody habit for the first angiosperms. All other "anthophytes" are woody; this includes extant gymnosperms, as well as those fossils typically considered close relatives of angiosperms (e.g., Caytoniales, Bennettitales).

However, the strictly aquatic water lily lineage (Nymphaeales) follows Amborella as the subsequent sister to all other flowering plants. As a result of the near-basal placement of Nymphaeaceae, the habit of the first flowering plants is reconstructed as equivocal on the basis of analyses of extant taxa (Soltis et al. 2005). Nonetheless, the early appearance of the water lily lineage, together with the discovery that some of the oldest angiosperm fossils are aquatic (e.g., Archaefructus), reinforced the hypothesis that the earliest angiosperms may have been aquatic - that is, "wet and wild" (D. Dilcher, pers. comm.; see Coiffard et al. 2007).

\section{Molecular Data and Divergence Times}

\section{Dating Origin of the Angiosperms}

In an attempt to estimate the timing of angiosperm origins, various authors have used a variety of different molecular data sets and estimation procedures. Although the oldest angiosperm fossils date to $132 \mathrm{Ma}$, molecular estimates have been somewhat older. Molecular estimates have dated angiosperm origins to the Lower Jurassic (175-200 Ma; Sanderson 1997; Sanderson \& Doyle 2001; Wikström et al. 2001; Bell et al. 2005; Magallón \& Sanderson 2005), to the Triassic (200-250 Ma; Sanderson \& Doyle 2001; Magallón \& Sanderson 2005), or even the Paleozoic (300 or 350 Ma; e.g., Ramshaw et al. 1972; Martin et al. 1989). However, in recent years, studies estimating the age of crown group angiosperms appear to be converging on estimates of between 140 and $180 \mathrm{Ma}$ (Sanderson et al. 2004; Bell et al. 2005; Moore et al. 2007). This apparent convergence in age estimation is probably due to the increased number of characters used, as well as the use of new "relaxed clock" methods that allow rates to vary across the tree (e.g., penalized likelihood, PATHd8, and Bayesian methods). Also, recent studies have used multiple fossils as either calibrations or maximum and minimum age constraints.

To date, the most comprehensive divergence time analysis for the angiosperms, for taxon sampling, is that of Wikström et al. (2001). The results from Wikström et al. (2001) have subsequently been used as a temporal framework for many ecological studies (e.g., Slingsby \& Verboom 2006; Vamosi et al. 2006; Edwards et al. 2007; Webb et al. 2007), as well as "external" calibration points for subsequent divergence time analyses of groups that may lack reliable fossils (e.g., Crayn et al. 2006; Park et al. 2006). Although a landmark study, the analysis of Wikström et al. suffered in several methodological ways that were unavoidable at the time because the necessary analytical tools were lacking, namely, reliance on one calibration point and the use of nonparametric rate smoothing (NPRS; a method that has been shown to be a biased estimator of clade ages).

Here we have reanalyzed the data set used by Wikström et al. by using multiple calibration points and age constraints (21 total; Table 1) and a tree topology (Fig. 3) inferred from a recent Bayesian analysis (Soltis et al. 2007). To make our results as comparable as possible to those of Wikström et al. (2001), we used their fossil calibration point as a fixed age in all analyses and inferred ages by using NPRS. We also used PATHd8 (Britton et al. 2007), a recently proposed relaxed-clock method to estimate divergence times across angiosperms. Like Wikström et al. (2001), we calculate a range of ages on the basis of branch length estimates from parsimony and maximum likelihood. Under the maximum likelihood criterion, a general-time-reversible model of sequence 
TABLE 1. Multiple Calibration Points and Age Constraints Used in Divergence Time Estimations

\begin{tabular}{|c|c|c|}
\hline Organism group & Age (Myr) & $\mathrm{MRCA}^{a}$ of: \\
\hline Altingia (Altingiaceae) & $88.5-90.4$ & Altingia and Paeonia \\
\hline Hamamelidaceae & $84-86$ & Daphniphyllum and Itea \\
\hline Cercidiphyllaceae & $65-71$ & Cercidiphyllum and Crassula \\
\hline Divisestylus (Iteaceae) & $89.5-93.5$ & Ribes and Itea \\
\hline Ailanthus (Simaroubaceae/Rutaceae/Meliaceae) & 50 & Ailanthus and Swietenia \\
\hline Burseraceae/Anacardiaceae & 50 & Bursera and Schinus \\
\hline Parbombacaceoxylon (Malvales s.1.) & $65.5-70.6$ & Thymea and Bombax \\
\hline Bedelia (Fagales) & 84 & Cucumis and Carya \\
\hline Paleoclusia (Clusia/ Hypericum) & 89-90 & Dicella and Mesua \\
\hline Illiciospermum (Illiciales) & 89-99 & Illicium and Schisandra \\
\hline Diplodipelta & 36 & Valeriana and Dipsacus \\
\hline Angiosperm Crown Group & $131.8(\mathrm{~min})$ & Amborella and Valeriana \\
\hline Eudicots (crown group) & 125 & Ranunculus and Valeriana \\
\hline Virginianthus (Calycanthaceae) & $98-113$ & Calycanthus and Idiospermum \\
\hline Unnamed (Chloranthaceae) & $98-113$ & Hedyosmum and Chloranthus \\
\hline Perisyncolporites (Malpighiales) & 49 & Dicella and Malpighia \\
\hline Pseudosalix (Malpighiales) & 48 & Idesia and Populus \\
\hline Cornales & 86 & Cornus and $\mathcal{N y s s a}$ \\
\hline Platanaceae & $98-113$ & Platanus and Placospermum \\
\hline Buxaceae & $98-113$ & Didymeles and Buxus \\
\hline Bignoniaceae & 49.4 & Catalpa and Verbena \\
\hline Bignoniaceae & 35 & Catalpa and Campsis \\
\hline
\end{tabular}

${ }^{a}$ MRCA, most recent common ancestor.

evolution was used. To accommodate amongsite rate variation, we used a discrete gamma $(\Gamma)$ distribution with four rate categories and accounted for the proportion of invariable sites (I) in the substitution model (Fig. 3).

The results of these analyses for some of the major early angiosperm groups are summarized in Table 2. In almost all cases, our NPRS dates, with either one or multiple fossils, were older than those of Wikström et al. (2001), potentially because we are using a slightly different tree topology (Soltis et al. 2007a), Likewise, across the nodes examined here, PATHd8 provided younger age estimates under each fossil treatment.

The mean absolute difference across all nodes using these methods was approximately 5 Myr, with nearly all differences being older in the multiple-calibration analysis than the single-calibration analysis. This finding is potentially significant given that the average bootstrap estimate of standard errors was less than these values. However, the difference at any specific node was greater than $10 \mathrm{Myr}$ for only three of the nodes. One explanation for the differences is that many of the minimum age constraints used in our study (seven of 20) were older than the ages inferred by Wikström et al. (2001), pushing ages further back in time from these constrained nodes.

Although there appears to be a convergence in the age estimates for angiosperms across different studies, new data (whether molecular or fossil), along with new estimation methods, will help to further refine our ideas of the age and time frame of angiosperm origins and diversification. With the interest in using large angiosperm phylogenies to investigate questions concerning ecology and comparative biology, along with the continual refinement in relationships among major angiosperm lineages, a new estimate of the ages of the major clades is much needed and should be pursued. 


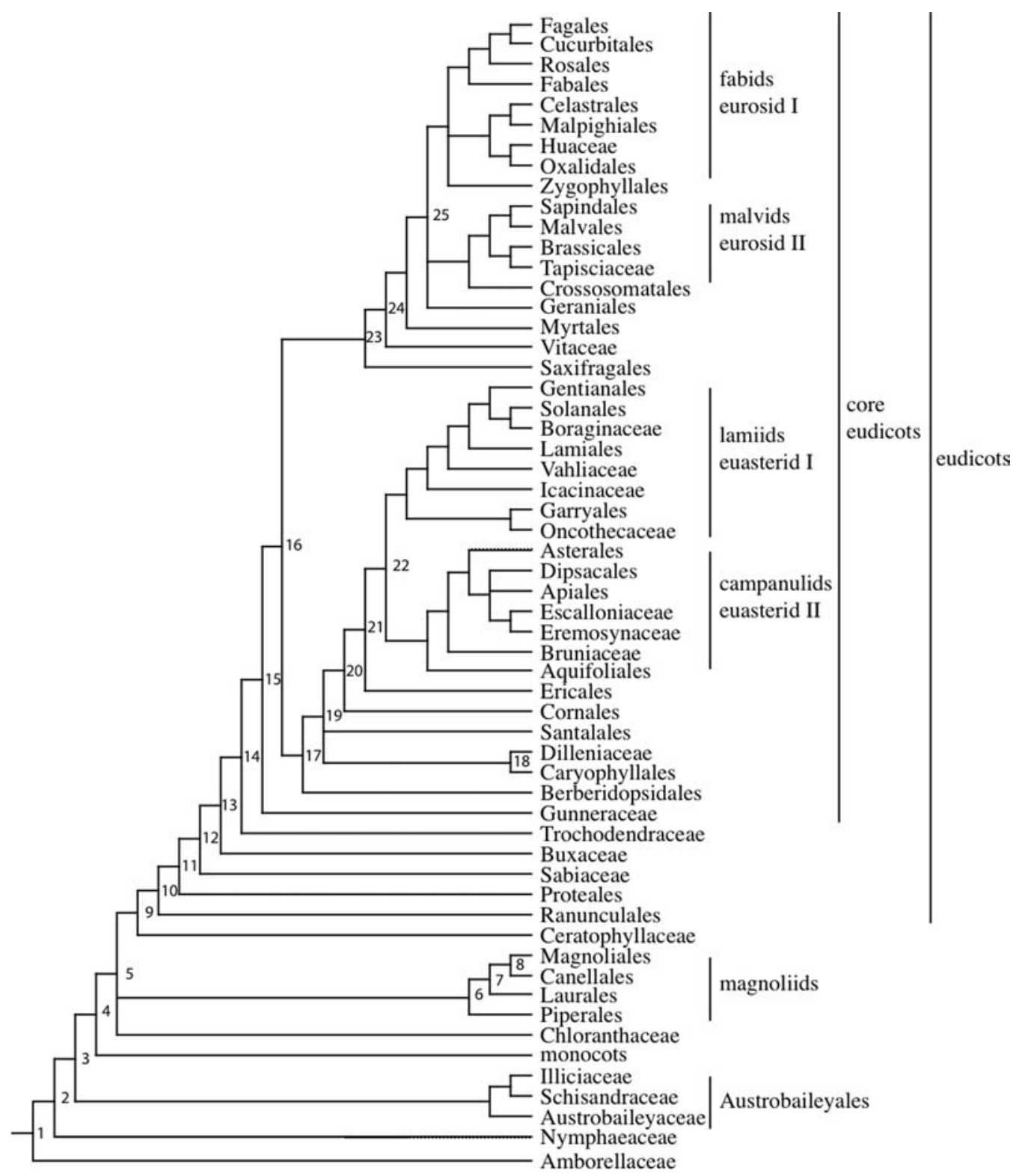

Figure 3. Divergence time estimates for major clades of angiosperms from a reanalysis of the threegene, 567-taxon data set by using multiple calibration points and methods (see text). Dates corresponding to numbered nodes are given in Table 1.

\section{Extant Members of "Old" Lineages Represent Recent Diversifications}

The divergence time estimates of Yoo et al. (2005) suggest that crown group Nymphaeales date to the Eocene (44.6$67.9 \mathrm{Ma}) ; \quad$ Nymphaeaceae and Cabombaceae split at that point. Extant genera of Nymphaeaceae began to diversify in the late
Eocene to early Oligocene (41.1-67.7 Ma), and the two extant genera of Cabombaceae diverged during the Miocene (19.9-65.6 Ma). These results indicate that extant Nymphaeales diversified relatively recently, whereas the stem lineage to Nymphaeales is old, on the basis of a fossil attributed to Nymphaeales from the Early Cretaceous (125-115 Ma; Friis et al. 2001). Although the Friis et al. fossil and a 
TABLE 2. Estimated Clade Ages (Myr)

\begin{tabular}{|c|c|c|c|c|c|c|}
\hline Clade no. ${ }^{a}$ & Clade & Wikstrom et al. ${ }^{b}$ & $\mathrm{NPRS}^{e}$ & PATHd $^{c}$ & $\mathrm{NPRS}^{d}$ & PATHd $^{d}$ \\
\hline 1 & Angiosperms & $158-179$ & $166-187$ & $152-171$ & $165-188$ & $164-173$ \\
\hline 2 & & $153-171$ & $159-179$ & $132-155$ & $161-180$ & $149-158$ \\
\hline 3 & & $147-165$ & $151-172$ & $127-142$ & $154-174$ & $138-146$ \\
\hline 4 & & $\underline{e}^{e}$ & $145-167$ & $125-135$ & $148-170$ & $132-140$ \\
\hline 5 & & - & $147-165$ & $126-136$ & $150-168$ & $131-140$ \\
\hline 6 & & $122-132$ & $140-159$ & $45-50$ & $145-162$ & 98 \\
\hline 7 & & $127-134$ & $135-153$ & $39-41$ & $139-156$ & 98 \\
\hline 8 & & $108-113$ & $118-144$ & $37-39$ & $118-146$ & 98 \\
\hline 9 & & $140-155$ & $144-157$ & $123-131$ & $146-160$ & $131-136$ \\
\hline 10 & Eudicots & $131-147$ & $135-149$ & $110-119$ & $136-152$ & 125 \\
\hline 11 & & $130-144$ & $131-146$ & $108-118$ & $132-149$ & $123-124$ \\
\hline 12 & & $128-140$ & $130-144$ & $107-117$ & $131-148$ & $122-123$ \\
\hline 13 & & $124-137$ & $124-139$ & $102-110$ & $125-142$ & $110-116$ \\
\hline 14 & & $123-135$ & $124-136$ & $100-106$ & $125-139$ & $107-113$ \\
\hline 15 & & $116-127$ & $118-129$ & 89-95 & 119-132 & $96-103$ \\
\hline 16 & & $114-124$ & $116-124$ & 84-90 & $117-128$ & 93-96 \\
\hline 17 & & $104-111$ & $106-113$ & $84-90$ & $109-117$ & 92-95 \\
\hline 18 & & $106-114$ & $107-113$ & $72-77$ & $110-117$ & 86 \\
\hline 19 & & - & $104-109$ & $71-76$ & $107-113$ & $79-81$ \\
\hline 20 & & $102-112$ & $91-104$ & $69-75$ & $96-108$ & $79-80$ \\
\hline 21 & & $114-125$ & $115-126$ & 86-92 & $120-130$ & $96-100$ \\
\hline 22 & & $111-121$ & $113-123$ & 85-89 & $116-126$ & $94-97$ \\
\hline 23 & & $108-117$ & $106-120$ & 85-89 & $109-124$ & 93-97 \\
\hline 24 & & $100-109$ & $97-110$ & 84 & $101-113$ & 87-89 \\
\hline
\end{tabular}

${ }^{a}$ Clade numbers refer to numbered nodes in Figure 3.

${ }^{b}$ Wikstrom et al. dates are given in their Supplemental Data, available online. Because we tried to estimate the age of the root, but with constraints as noted, it is possible that a range of solutions might exist. For each analysis, we fixed two ages: (1) the age of the root node (most recent common ancestor of seed plants) at $310 \mathrm{Myr}$ and (2) the age of the most recent common ancestor of Cucurbitales and Fagales at 84 Myr.

${ }^{\circ}$ Based on single fixed calibration of the most recent common ancestor of Cucurbitales and Fagales at 84 Myr.

${ }^{d}$ Based on 20 minimum age constraints in addition to single fixed calibration of the most recent common ancestor of Cucurbitales and Fagales at 84 Myr.

${ }^{e}$ Node not compatible with tree used.

fossil attributed to Nymphaeaceae from the middle Cretaceous (90 Ma; Gandolfo et al. 2004) may be best placed deeper in the angiosperms, there is a distinct gap between the origin of Nymphaeales and its diversification into modern lineages.

These results for Nymphaeales indicating recent diversification in an ancient lineage agree with similar findings for the basal angiosperms Chloranthaceae (Zhang \& Renner 2003) and Illicium (Illiciaceae; Morris et al. 2007). The fossil record indicates clearly that Chloranthaceae represent one of the oldest angiosperm lineages, with unequivocal reproductive struc- tures resembling those of Hedyosmum from the Barremian-Aptian boundary, approximately 125 Ma (see Friis et al. 1994, 1999; Frïs 1997; Doyle et al. 2003; Eklund et al. 2004). However, divergence time estimates based on molecular data indicate that the extant genera of Chloranthaceae are relatively young (i.e., 60-29 Ma for Hedyosmum, 22-11 Ma for Chloranthus, and 18-9 Ma for Ascarina; Zhang \& Renner 2003).

Similar results have been obtained for Illicium (Illiciaceae). Morris et al. (2007) estimated divergence times within Illicium by using penalized likelihood and multiple calibration points. The Illicium crown group appears to have arisen 
during the Cretaceous; Frumin and Friis (1999) identified Illiciospermum pusillum as the first unequivocal evidence of the family, with an estimated age of 89-99 Ma. However, extant New World taxa diversified as recently as the Miocene or Pliocene.

\section{Many Diversifications Occurred in a Narrow Window}

Many of the divergences of major clades of angiosperms occurred rapidly. For example, molecular dating techniques provide a time frame for the likely rapid diversification of the five major lineages of Mesangiospermae (magnoliids, monocots, Chloranthaceae, eudicots, Ceratophyllaceae) - this diversification, ultimately yielding perhaps $97 \%$ of all angiosperm species, was rapid, occurring over a span of perhaps no more than $5 \mathrm{Myr}$ (Moore et al. 2007). In perspective, this span represents a time frame comparable to the rapid radiation of the Hawaiian silversword alliance (AsteraceaeMadiinae), which putatively arose from a North American ancestor $5 \mathrm{Ma}$ (Baldwin \& Sanderson 1998; Barrier et al. 1999).

But how does the rapid radiation or big bang of major angiosperm lineages (Mesangiospermae) compare to the proposed rapid divergences within other major lineages of life? The fossil record provides evidence for a similar big bang for an early Tertiary ( $65 \mathrm{Ma})$ explosion of modern bird orders (Feduccia 2003) that may have occurred over a time frame of just 5-10 Myr (Feduccia 2003), a somewhat longer time frame than that estimated for the diversification of Mesangiospermae. Interestingly, molecular dating is in conflict with the fossil record and has consistently placed the appearance of modern birds as much older (at least $100 \mathrm{Ma}$; reviewed in Feduccia 2003).

Fossil evidence similarly has suggested an explosive Tertiary radiation of placental mammals (Novacek 1999; Archibald \& Deutschuman 2001; Bloch et al. 2007; Wible et al. 2007). However, as with birds, a recent analysis of mammals performed with sequence data and a supertree approach again indicates that the radiation of living placental mammals is older, occurring perhaps between 100 and $80 \mathrm{Ma}$; the "phylogenetic fuses" leading to the diversification of placental mammals were "much longer than previously expected" (Bininda-Emonds et al. 2007). That is, the diversification of modern mammals as a clade was not as rapid as previously thought.

However, radiations of lineages within the mammals do appear to have been rapid, on the basis of both molecular and fossil evidence. Klaus and Miyamoto (1991) provided an estimate of approximately 5 Myr for the diversification of the major lineages of pecoran ruminants. These are the large, even-toed, hoofed mammals (all belonging to one eutherian mammal order and one infraorder), and their rapid cladogenesis is supported by both molecular and fossil evidence. Allard et al. (1992) provided a similar window for the diversification of the major bovid lineages (bison, cattle, and buffalo), a radiation supported by molecular and fossil evidence.

In contrast to data for all mammals and birds, molecular and fossil data are in close agreement for the timing of both the origin and early diversification of angiosperms (reviewed in Bell et al. 2005). Furthermore, the speed (< $5 \mathrm{Myr})$ and magnitude $(\sim 350,000-400,000$ extant species) of the explosive radiation of flowering plants may be unique.

Subsequent radiations within the clades of Mesangiospermae also occurred rapidly. For example, the Saxifragales and rosid clades also diversified over similar and narrow time spans (Jian et al., 2008; Wang et al., submitted). The rapid diversification within the rosids (Wang et al., submitted) may be of particular importance in that the inferred bursts of diversification correspond in timing with the rapid rise of angiosperm-dominated forests, as suggested by the fossil record (Crane 1987; Upchurch \& Wolfe 1993).

The rosid diversification also corresponds to the diversification of several other lineages that apparently evolved in parallel with the 
diversification of angiosperm forests (crown group rosids originated $110 \quad[ \pm 6]$ to $93[ \pm 6] \mathrm{Ma}$, followed by rapid diversification into the eurosid I and eurosid II clades around $108[ \pm 6]$ to $91[ \pm 6] \mathrm{Ma}$ and $107[ \pm 6]$ to 83 [ \pm 7$] \mathrm{Ma}$ ): ants (Moreau et al. 2006), beetles, and hemipterans (Farrell 1998; Wilf et al. 2000). Slightly later diversificationsamphibians (Roelants et al. 2007), ferns (Schneider et al. 2004), and primates (Bloch et al. 2007) - appear to have closely tracked the rise of rosid-dominated forests (Wang et al., submitted). A similar window of diversification is seen in tree species in clades other than the rosids. Cornales of the asterid clade also appear to have diversified during this same window of time (e.g., Bremer et al. 2004; Xiang, pers. comm.), as did the woody members of Saxifragales (e.g., Altingiaceae; Jian et al., 2008).

\section{Genome Evolution}

Polyploidy has long been recognized as a major evolutionary force in many plant lineages, particularly ferns and angiosperms (Stebbins 1950; Grant 1981; Soltis \& Soltis 1999). Although polyploidy is considered common in angiosperms, its actual frequency has been debated. Classic studies using base chromosome numbers estimated that $30 \%-60 \%$ of angiosperms might be of polyploid origin (Muntzing 1936; Darlington 1937; Stebbins 1950; Grant 1981). But recent genomic studies reveal evidence of ancient polyploidy in virtually all angiosperm genomes investigated to date (e.g., Vision et al. 2000; Bowers et al. 2003; Blanc \& Wolfe 2004; Paterson et al. 2004), indicating that all angiosperms may have experienced one or more rounds of genome duplication. Analysis of the complete genome sequence of Arabidopsis suggested three ancient polyploidy events, one within the Brassicales, as well as two more ancient duplication events; these two more ancient whole-genome duplications were suggested to have occurred (1) before, or coincident with, the origin of the an- giosperms and 2) just before or coincident with the divergence of major core eudicot lineages (Bowers et al. 2003). From analyses of the complete genome sequence of grape (Vitis), Jaillon et al. (2007) suggest that the common ancestor of Vitis, Populus, and Arabidopsis was an ancient hexaploid that arose after the monocot-versuseudicot split. After the formation of this paleohexaploid, there were subsequent genomewide duplication events in the Brassicales and Populus lineages (Fig. 4). However, in their independent analysis of the grape genome, Velasco et al. (2007) proposed that Vitis experienced a more recent whole, or perhaps large-scale, genome duplication event. Velasco et al. proposed an alternative scenario: three genomewide duplication events in Arabidopsis and Populus, one of which was shared by all eudicots (and perhaps the monocots), as well as one duplication event shared by Arabidopsis and Populus, with a third event specific to each lineage. They suggested that Vitis has the genomewide duplication event shared by all eudicots, as well as a lineage-specific event that may be the result of hybridization (Fig. 4). From these initial comparisons of the first complete nuclear genome sequences, genomewide duplications clearly have frequently occurred, although the exact phylogenetic placements of many of these events remain unclear.

Other genomic investigations using large expressed sequence tag (EST) data set indicate that polyploidy has been prevalent in many angiosperm clades (Blanc \& Wolfe 2004), including most crops and several basal angiosperm lineages and a basal eudicot (Cui et al. 2006). Signatures of whole-genome duplications are present in the water lily Nuphar (Nymphaeales), Acorus (Acoraceae, the sister to all other monocots), and the magnoliids Persea (Lauraceae) and Liriodendron (Magnoliaceae) corroborating evidence for ancient duplication based on isozymes (Soltis \& Soltis 1990) — and the basal eudicot Eschscholzia californica (California poppy, Papaveraceae), a member of Ranunculales. However, analyses of ESTs from Amborella, the sister to all other extant 

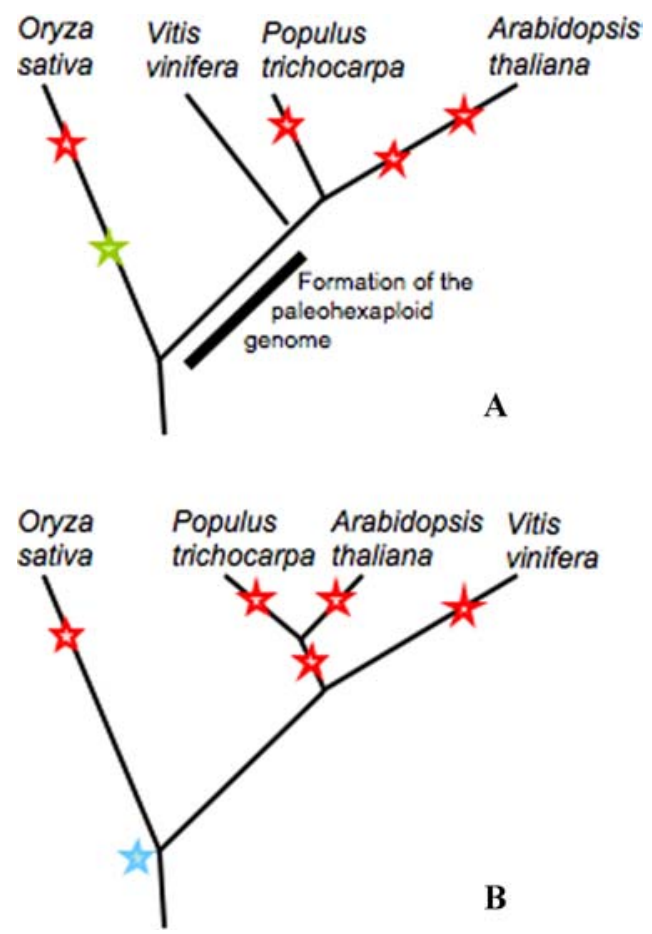

Figure 4. Two hypotheses for genome-wide duplication events in angiosperm evolution on the basis of nuclear genomes sequenced to date. Each star indicates a whole-genome duplication event on that branch. (A) Formation of the paleohexaploid ancestral genome occurred after the divergence of eudicots from monocotyledons and before the radiation of the rosids (Jaillon et al. 2007); no recent duplication is proposed in grape. Tree redrawn to show Vitis sister to all other rosids (Soltis et al. 2005). (B) Three rounds of duplications are proposed for both Arabidopsis and Populus (Bowers et al. 2003; Macer et al. 2005; Tuskan et al. 2006; Velasco et al. 2007); recent duplication in grape. Yellow star indicates that the duplication event is apparent in the rice genome, but its presence in other monocotyledons is unclear. Blue star indicates a duplication putatively shared by all eudicots (and possibly all monocots). In color in Annals online.

angiosperms, have so far not revealed evidence of ancient polyploidy. How many of these whole-genome duplications resulted from shared polyploidization events? Genomic data for additional taxa are needed, but additional evidence for genome duplication is obtainable from analyses of gene families across the angiosperms, without reliance on whole-genome sequences or even large EST sets.
Many crucial genes that control floral initiation and development appear to have been duplicated either just before, or early in, angiosperm evolution; other floral developmental regulators experienced duplication later, near the origin of the core eudicots, a major clade that constitutes $75 \%$ of all flowering plants (Kramer et al. 2003; Kim et al. 2004; Zahn et al. 2005; Irish 2006; Kramer \& Zimmer 2006). These coincident gene duplications may have resulted from whole-genome duplication rather than independent gene duplications.

Several MADS-box genes, which are crucial regulators of many aspects of plant development, show this pattern of gene duplication. For example, extant gymnosperms have one Bfunction homologue, whereas all angiosperms have at least two homologues of the Arabidopsis genes AP3 and PI, respectively. The two Bfunction gene lineages, accommodating homologues of $A P 3$ and PI, originated by duplication of one B-function gene before the origin of the angiosperms, perhaps as much as $260 \mathrm{Ma}$ (Kim et al. 2004). Another gene duplication event also occurred before the origin of the angiosperms, in the $\mathrm{C}$-function lineage, leading to two lineages in angiosperms, one with $A G$ homologues having roles in stamen and carpel identity and the other with ovule-specific D function (Kramer et al. 2004). Similarly, SEP genes were duplicated to form the $A G L 2 / 3 / 4$ (SEP1/2/4) and AGL9 (SEP3) lineages in the common ancestor of the angiosperms (Zahn et al. 2005). The corresponding duplications of these key floral organ identity genes before the origin of the angiosperms may have somehow facilitated diversification and innovation of the plant reproductive program, ultimately resulting in the origin of the flower itself (Buzgo et al. 2005; Zahn et al. 2005). The timing of the Cfunction and SEP gene duplications has not been ascertained, however.

Other MADS gene duplications, including the APETALA1, APETALA3, SEP, and AGA$M O U S$ lineages, occurred near the origin of the eudicots (Litt \& Irish 2003; Kramer et al. 2004; Zahn et al. 2005, 2006; Irish 2006). 
After the divergence of Buxaceae, the Bfunction gene $A P 3$ was duplicated to form the euAP3 and TM6 lineages in core eudicots; then the TM6 gene was lost in several rosids (Kramer et al. 1998). Again, the data indicate that MADS duplications might have played an important role in the diversification of the flower.

Still other genes, not directly involved in controlling floral organ identity, also appear to have been duplicated just before the origin of the angiosperms, or near the origin of the eudicot clade. For example, an rpb2 gene duplication occurred either early in core eudicot evolution or at or near the time of the Buxaceae-Trochodendraceae divergence (Luo et al. 2007). The question remains: Were these duplications part of events in which the entire angiosperm genome was duplicated, or were these independent gene duplication events? As the cost of gene and genome sequencing continues to drop, the data will soon be available to address the fascinating hypothesis that whole-genome duplications may have served as catalysts for key innovations in angiosperm evolution.

\section{Floral Developmental Genetics}

Although the flower is obviously the central feature of the angiosperms, the origin of the flower and subsequent diversification remain as major evolutionary questions. The ABC model (now often referred to as the ABCE model) has been the unifying paradigm for floral developmental genetics for more than a decade (Coen \& Meyerowitz 1991). However, it is based on the phylogenetically derived eudicot model systems Arabidopsis (Bowman et al. 1989) and Antirrhinum (snapdragon) (Schwarz-Sommer et al. 1990; Davies et al. 2006), with complementary data from other eudicot systems, including Petunia (Rijpkema et al. 2006) and Gerbera (Teeri et al. 2006). Multifaceted research collaborations involving phylogenetics, classical developmental studies, genomics, and developmental genetics have recently provided valuable new insights into the early flower and to early angiosperm diversification. We provide an overview here (for more detailed summaries, see Frohlich 2006; Soltis et al. 2006, 2007b).

The ABC model posits that floral organ identity is controlled by three gene functions, A, B, and $\mathrm{C}$, that act in combination to produce the floral organs; A-function alone specifies sepal identity, A- and B-functions together control petal identity; B- and C-functions together control stamen identity; C-function alone specifies carpel identity (Fig. 5). Several genes have been identified that act as key regulators in determining floral organ identity in the model eudicots, such as Arabidopsis and Antirrhinum. For example, in Arabidopsis, APETALA1 (AP1) and AP2 are the A-function genes, AP3 and PISTILLATA $(P I)$ are the B-function genes, and AGAMOUS $(A G)$ is the C-function gene. In Antirrhinum, the homologous gene (or homologue) that is comparable to AP1 is termed SQUAMOSA. Details regarding A-function remain complex, however, with A-function not clearly documented except in Arabidopsis. The homologues of the A-function gene AP2 in Antirrhinum are LIPLESS1 and LIPLESS2; these may provide partial A-function in snapdragon (Keck et al. 2003). The B-function genes in Antirrhinum are DEFICIENS (DEF) and GLOBOSA (GLO), which are homologues of $A P 3$ and $P I$, respectively. The C-function gene in Antirrhinum is PLENA (PLE). All these genes, with the exception of $A P 2$ (and its homologues), are MADS-box genes (Theissen et al. 2000), a broad family of eukaryotic genes that encode transcription factors containing a highly conserved DNA-binding domain (MADS domain).

The ABC model has been updated to accommodate new results, including the identification of additional MADS-box genes that control ovule identity (D-function; Colombo et al. 1995) and those that contribute to sepal, petal, stamen, and carpel identity (E-function; Pelaz et al. 2000). We will not consider D-function further here because ovules (these become seeds after fertilization) are not discrete floral organs as are sepals, petals, stamens, and carpels. 
A

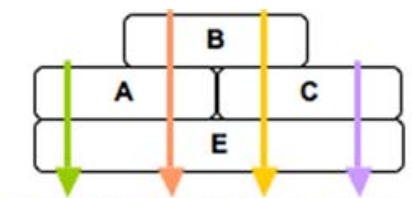

$A+E \quad A+B+E \quad B+C+E \quad C+E$

Sepal Petal Stamen Carpel

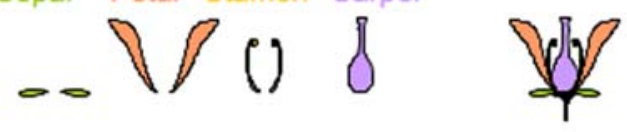

B

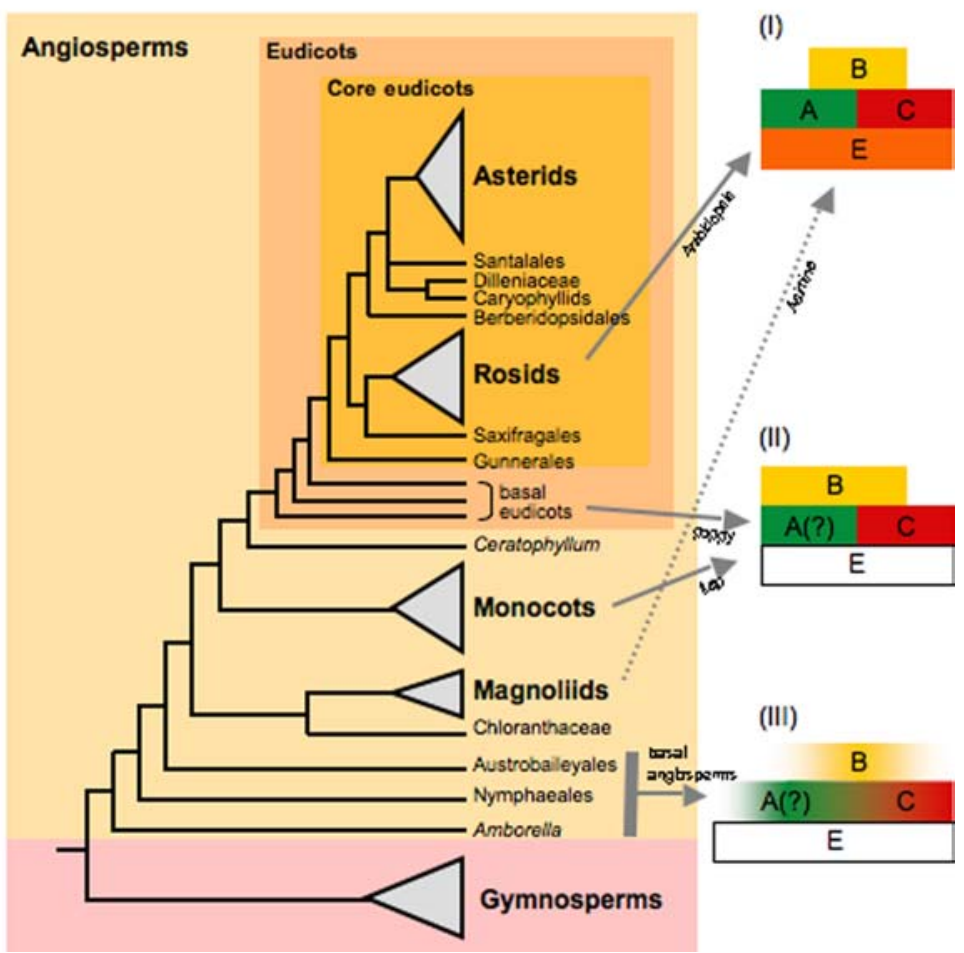

Figure 5. Angiosperm floral developmental genetics. (A) Classic ABCE model (Coen \& Meyerowitz 1991; Pelaz et al. 2000). (B) Summarized phylogenetic tree for flowering plants with placements of model organisms. Known or postulated expression patterns are shown on the right for organ identity genes: (I) $A B C$ model developed for core eudicots (Coen \& Meyerowitz 1991) may also be applicable to Asimina, which is included in the magnoliid clade; (II) an example of the "shifting boundary model" applied to some basal eudicots (Kramer \& Irish 2000) and monocots (Kanno et al. 2003); (III) "fading borders" model proposed for basal angiosperms (Buzgo et al. 2004; Kim et al. 2005).

However, E-function plays a major role in the formation of floral organs and is closely allied with $\mathrm{ABC}$ functions.

The E-function genes in Arabidopsis are SEPALLATA1 (SEP1), -2, -3, and -4 (Pelaz et al. 2000). SEP proteins, together with the protein products of the $\mathrm{ABC}$ genes, are required to specify floral organ identity. The SEP genes are functionally redundant in their control of the four floral organ identities - sepals, petals, stamens, and carpels. On the basis of studies in Arabidopsis, A + E function is needed for sepals, $\mathrm{A}+\mathrm{B}+\mathrm{E}$ function for petals, $\mathrm{B}+\mathrm{C}+\mathrm{E}$ function for stamens, and $\mathrm{C}+\mathrm{E}$ function for carpels (Fig. 5). Hence, a more appropriate abbreviation for the current model of floral 
organ identity in Arabidopsis and Antirrhinum is the ABCE model, a designation we use here.

Expression patterns of MADS-box genes in eudicots and grasses typically support the ABC (now the ABCE) model. For example, strong expression of eudicot AP3 and PI homologues is typically limited to petals and stamens, where these genes are required for organ identity specification (Ma \& dePamphilis 2000). Studies stemming from the Floral Genome Project (Soltis et al. 2002, 2006, 2007; Albert et al. 2005) have provided some of the first insights into floral organ identity genes and their patterns of expression in basal angiosperms (Soltis et al. 2006). The expression of MADS-box genes in basal angiosperm flowers is generally consistent with the ABC model; however, the expression patterns in basal angiosperms are often broader than expected based on the ABC model (Kim et al. 2005). In particular, the homologues of B-function genes, AP3 and PI, are broadly expressed in tepals, stamens, and carpels in many basal angiosperms, including representatives of the three basalmost lineages, Amborella, water lilies, and Illicium of Austrobaileyales, as well as in members of the magnoliid clade (e.g., Magnolia) (Fig. 5).

The floral developmental genetics studies conducted to date for basal angiosperms indicate a broader pattern of expression of $\mathrm{B}$ (and to a lesser extent, $\mathrm{C}$ and $\mathrm{E}$ )-function homologues in basal angiosperms than in eudicots (Kim et al. 2005). These results indicate that the ABC model as developed for eudicots is not perfectly applicable to basal angiosperms and, by inference, the earliest angiosperms. The floral morphology of many basal angiosperms provides a crucial hint to what may be a more appropriate model for these plants. In Amborella and other basal angiosperms (e.g., Illicium), floral organs are spirally arranged, with a gradual transition from bracts to outer and inner tepals, from tepals to stamens, and finally to carpels (Fig. 5). These gradual intergradations of floral organs cannot be easily explained by the classic ABC model and, together with the data obtained from floral developmental stud- ies (briefly reviewed here), resulted in the fading borders model (Buzgo et al. 2004, 2005). This model proposes that the gradual transitions in floral organ morphology result from a gradient in the level of expression of floral organ identity genes across the developing floral meristem (Fig. 5). Weak expression at the margin of a gene's range of "activity" overlaps with the expression of another regulator in adjacent cells. This pattern of overlapping expression would result in the formation of morphologically intermediate floral organs rather than organs that are clearly distinct. Recent data from the expression of B-function genes in Amborella lend support to this model (reviewed in Soltis et al. 2006, 2007b).

The ABC model of floral organ identity is typically considered the default program, with variants viewed as derivatives of this program. In fact, however, when gene expression profiles of floral-organ regulators are compared in a phylogenetic context, the ABC model of Arabidopsis is clearly evolutionarily derived. The ancestral flower had broad expression patterns of at least B-function regulators; broad and overlapping expression yielded morphologically intergrading floral organs, as seen in several extant basal angiosperms. Restriction of expression (and function) to specific regions of the floral meristem resulted in the discrete whorls of morphologically distinct floral organs that together characterize most of the eudicots and certainly all the core eudicots. Further investigation of the evolution of the floral regulatory network should rely on the phylogenetic perspective, which reveals that the ABC model is derived.

But how was the genetic machinery necessary for specifying a flower assembled in the first place? Were the genes co-opted from other processes and integrated into a pathway gradually, or were they brought together more suddenly, perhaps through gene or whole-genome duplication? Parallel duplications of floral regulatory genes suggest whole-genome duplications in the common ancestor of extant angiosperms and the common ancestor of core eudicots. 
However, the mere duplication of a genome or set of genes was probably not coincident with the origin of morphological novelty. Certainly some time would have been needed for the assembly of a functional floral-organ specification program in the ancestral angiosperm. Furthermore, the duplication of the B-function homologues (AP3 and $P I)$ apparently occurred approximately $260 \mathrm{Ma}, 130 \mathrm{Myr}$ before the first fossil evidence of angiosperms. The process of assembling a new genetic program and its translation into morphological innovation merits further study.

Studies of floral developmental genetics have also provided more insights into the evolution of the perianth. The classical view of angiosperm flower evolution maintains that stamens and carpels evolved just once, whereas the sterile perianth organs may have arisen multiple times (e.g., Eames 1961; Takhtajan 1991). This reasoning is based on the idea that angiosperms are derived from apetalous ancestors and that the perianth is an evolutionary novelty. The resemblance of sepals to foliar bracts and of petals to stamens has encouraged the view that sepals are evolutionarily derived from foliar bracts and petals, from stamens. The longstanding view is that such stamen-derived petals, called andropetals (Takhtajan 1991), are associated primarily with eudicots. The perianth of basal angiosperms typically consists of morphologically similar organs, termed tepals (Endress 2001), which could be assigned bracteal (bracteopetal) or staminal (andropetal) origins depending on whether sepallike or petallike features prevail. By these criteria, the tepals of Lauraceae have been considered bracteopetalous (Albert et al. 1998; de Craene et al. 2003). However, expression data for Persea (based on reverse transcription-polymerase chain reaction, fluorescence in situ hybridization, and microarrays), coupled with developmental data, suggest that the "petals" of Persea and other Lauraceae clearly are of staminal origin (Chanderbali et al. 2006 , in prep.). These data clearly document that, as long suggested, not all "petals" are homologous. It will be of interest to examine the origin of petals in other basal lineages by using molecular data.

\section{Synthesis, Pragmatism, and the Future}

During the past decade, we have witnessed dramatic changes in perspective of some fundamental aspects of the origin and early evolution of flowering plants. For example, the anthophyte hypothesis has come and goneand possibly come back again in a resurrected form. Likewise, the view of the first flower has changed from something large and Magnolialike to a diminutive form that performed the key function of the flower - reproduction-but that only vaguely resembled most modern flowers. These complex changes in our collective views have been triggered by syntheses of phylogenetics, paleobotany, developmental biology, and genetics. Such broad changes of thought rarely emerge without multidisciplinary synthesis, and our understanding of angiosperm evolution has benefited from a general attitude of collaboration and cooperation among scientists in different disciplines.

Despite this progress, some issues will remain difficult to resolve: What is really the sister group of the angiosperms? How was the genetic machinery that underlies the flower assembled? What role has polyploidy played in the origin and diversification of the angiosperms? What geological and biological factors stimulated angiosperm radiations, and what effects did these radiations have on the rest of Earth's biota? Although difficult, these questions can likewise be addressed through collaboration and multidisciplinary study and with patience. The next decade - perhaps the "postphylogenetic period"-holds tremendous opportunities for advancing our understanding of the events and processes that shaped the origin and early evolution of angiosperms.

New discoveries in paleobotany-through new fossils, new methods, and new interpretation (e.g., Friis et al. 2007)—will continue to revise and enhance our understanding of 
angiosperm origins and early evolution. Studies of codiversification among major clades of life, coupled with improved understanding of climatic events in Earth's history, will lead to new views of the processes that build communities and ecosystems and how those processes have shaped today's biota. Finally, genomic analysis of nonmodel systems holds countless clues to the origin and early diversification of angiosperms. For example, ongoing genomic studies of phylogenetically key basal angiosperms (Amborella, Nuphar, Persea, Liriodendron, and Aristolochia) are providing crucial data for inferring the role of polyploidy in early angiosperm evolution (http://www.ancestralangiosperm.org). Eventually, complete genome sequences for one or more of these early angiosperms will enable analyses of polyploidy, genome evolution, and the assembly of genetic pathways and networks. With rapid advances in next-generation sequencing techniques and their application to comparative genomics (e.g., Moore et al. 2006; Wall et al. submitted), genome sequences for evolutionarily important species may soon be forthcoming. The Amborella nuclear genome is an extremely strong candidate for sequencing (Soltis et al. 2008). Not only is Amborella the sister to all other extant angiosperms, thus providing an evolutionary reference for all other studies, but genomic resources are already in place.

\section{Conflicts of Interest}

The authors declare no conflicts of interest.

\section{References}

Albert, V.A., M.H.G. Gustafsson \& L. Di Laurenzio. 1998. Ontogenetic systematics, molecular developmental genetics, and the angiosperm petal. In Molecular Systematics of Plant II. P.S. Soltis, D.E. Soltis \& J.J. Doyle, Eds.: 349-374. Kluwer Academic. Boston.

Albert, V.A., D.E. Soltis, J.E. Carlson, et al. 2005. Floral gene resources from basal angiosperms for comparative genomics research. BMC Plant Biol. 5: 5-16.

Allard, M.W., M.M. Miyamoto, L. Jarecki, et al. 1992. DNA systematics and evolution of the artiodactyl family Bovidae. Proc. Natl. Acad. Sci. USA 89: 39723976.

APG II. 2003. An update of the Angiosperm Phylogeny Group classification for the orders and families of flowering plants. Bot. F. Linn. Soc. 141: 399-436.

Archibald, J.D. \& D.H. Deutschuman. 2001. Quantitative analysis of the timing of the origin and diversification of extant placental orders. 7. Mamm. Evol. 8: 107124.

Baldwin B.G. \& M.J. Sanderson. 1998. Age and rate of diversification of the Hawaiian silversword alliance (Compositae). Bot. 7. Linn. Soc. 95: 94029406.

Barrier, M., B.G. Baldwin, R.H. Robichaux \& M.D. Purugganan. 1999. Interspecific hybrid ancestry of a plant adaptive radiation: allopolyploidy of the Hawaiian silversword alliance (Asteraceae) inferred from floral homeotic gene duplications. Mol. Biol. Evol. 16: 1105-1113.

Barkman, T.J., G. Chenery,J.R. McNeal, et al. 2000. Independent and combined analysis of sequences from all three genomic compartments converge to the root of flowering plant phylogeny. Proc. Natl. Acad. Sci. USA 97: 13166-13171.

Bell, C.D., D.E. Soltis \& P.S. Soltis. 2005. The age of the angiosperms: a molecular time-scale without a clock. Evolution 59: 1245-1258.

Bininda-Emonds, O.R.P., M. Cardillo, K.E. Jones, et al. 2007. The delayed rise of present-day mammals. $\mathrm{Na}$ ture 446: $507-512$.

Blanc, G. \& K.H. Wolfe. 2004. Widespread paleopolyploidy in model plant species inferred from age distribution of duplicate genes. Plant Cell 16: 16671678.

Bloch, J.I., M.T. Silcox, D.M. Boyer \& E.J. Sargis. 2007. New Paleocene skeletons and the relationship of plesiadapiforms to crown-clade primates. Proc. Nat. Acad. Sci. USA 104: 1159-1164.

Borsch, T., K.W. Hilu, D. Quandt, V, et al. 2003. Noncoding plastid trn T-trnF sequences reveal a well resolved phylogeny of basal angiosperms. 7. Evol. Biol. 16: $558-576$.

Bowers, J.E., B.A. Chapman, J. Rong \& A.H. Paterson. 2003. Unraveling angiosperm genome evolution by phylogenetic analysis of chromosomal duplication events. Nature 422: 433-438.

Bowman, J.L., D.R. Smyth \& E.M. Meyerowitz. 1989. Genes directing flower development in Arabidopsis. Plant Cell 1: 37-52.

Bremer, K., E.M. Friis \& B. Bremer. 2004. Molecular phylogenetic dating of asterid flowering plants shows early Cretaceous diversification. Syst. Biol. 53: 496 505.

Britton, T., C.L. Anderson, D. Jacquet, et al. 2007. Estimating divergence times in large phylogenetic trees. System. Biol. 56: 741-752. 
Burleigh, J.G. \& S. Mathews 2004. Phylogenetic signal in nucleotide data from seed plants: implications for resolving the seed plant tree of life. Am. F. Bot. 91: 1599-1613.

Buzgo, M., D.E. Soltis \& P.S. Soltis. 2004. The role of developmental morphology in molecular developmental genetics. Trends Plant Sci. 9: 1360-1385.

Buzgo, M., D.E. Soltis \& P.S. Soltis. 2005. The making of the flower. Biologist 52: 149-154.

Cantino, P., J. Doyle, S. Graham, et al. 2007. Towards a phylogenetic nomenclature of Tracheophyta. Taxon 56: 822-846.

Carlquist, S. \& E.L. Schneider. 2001. Vegetative anatomy of the New Caledonia endemic Amborella trichopoda: relationships with the Illiciales and implications for vessel origin. Pac. Sci. 55: 305-312.

Carlquist, S. \& E.L. Schneider. 2002. The tracheid-vessel element transition in angiosperms involves multiple independent features: cladistic consequences. Am. $\mathcal{F}$. Bot. 89: 185-195.

Chaw, S.M., C.L. Parkinson, Y. Cheng, et al. 2000. Seed plant phylogeny inferred from all three plant genomes: monophyly of extant gymnosperms and origin of Gnetales from conifers. Proc. Natl. Acad. Sci. USA 97: 4086-4091.

Coen, E.S. \& E.M. Meyerowitz. 1991. The war of the whorls: genetic interactions controlling flower development. Nature 353: 31-37.

Coiffard, C., B. Gomez \& F. Thevenard. 2007. Early Cretaceous angiosperm invasion of western Europe and major environmental changes. Ann. Bot. 100: 545553.

Chanderbali, A., S. Kim, M. Buzgo, et al. 2006. Genetic footprints of stamen ancestors guide perianth evolution in Persea (Lauraceae). Int. 7. Plant Sci. 167: 1075-1089.

Colombo, L., J. Franken, E. Koetje, et al. 1995. The petunia MADS box gene FBP11 determines ovule identify. Plant Cell 7: 1859-1868.

Crane, P.R. 1985. Phylogenetic analysis of seed plants and the origin of angiosperms. Ann. Missouri Bot. Garden 72: 716-793.

Crane, P.R. 1987. Vegetational consequences of the angiosperm diversification. In The Origins of $\mathrm{An}$ giosperms and their Biological Consequences. E.M. Friis, W.G. Chaloner \& P.R. Crane, Eds.: 107-144. Cambridge University Press. Cambridge, UK.

Crayn, D.M., R. Maurizio \& DJ. Maynard. 2006. Molecular phylogeny and dating reveals an Oligo-Miocene radiation of dry-adapted shrubs (former Tremandraceae) from rainforest tree progenitors (Elaeocarpaceae) in Australia. Am. f. Bot. 93: 1328-1342.

Gui, L., P.K. Wall, J. Leebens-Mack, et al. 2006. Widespread genome duplications throughout the history of flowering plants. Genome Res. 16: 738-739.
Darlington, G.D. 1937. Recent Advances in Cytology, 2nd ed. P. Blakiston's Son and Co. Philadelphia, PA.

Davies B., M. Cartolano \& Z. Schwarz-Summer. 2006. Flower development: the Antirrhinum perspective. In Advances in Botanical Research, vol. 44. D.E. Soltis, P.S. Soltis \& J. Leebens-Mack, Eds.: 279-315. Elsevier. New York.

De Craene, L.P.R., P.S. Soltis \& D.E. Soltis. 2003. Evolution of floral structures in basal angiosperms. Int. $\mathcal{F}$. Plant Sci. 164: S329-S363.

Dhingra, A. \& K.M. Folta. 2005. ASAP: amplification, sequencing and annotation of plastomes. $B M C G e-$ nomics 6: 176.

Donoghue, M.J. \& J.A. Doyle. 2000. Seed plant phylogeny: demise of the anthophyte hypothesis? Curr. Biol. 10: R106-R109.

Doyle, J.A. 2007. Integrating molecular phylogenetic and paleobotanical evidence on origin of the flower. Int. 7. Plant Sci. Submitted.

Doyle, J.A. 1998. Molecules, morphology, fossils, and the relationships of angiosperms and Gnetales. Mol. Phylogenet. Evol. 9: 448-462.

Doyle, J.A. 1996. Seed plant phylogeny and the relationships of Gnetales. Int. F. Plant Sci. 157: S3-S39.

Doyle, J.A. 2001. Significance of molecular phylogenetic analyses for paleobotanical investigations on the origin of angiosperms. Palaeobotanist 50: 167-188.

Doyle, J.A. \& M.J. Donoghue. 1986. Seed plant phylogeny and the origin of the angiosperms: an experimental cladistic approach. Bot. Rev. 52: 321-431.

Eames, A.J. 1961. Morphology of the Angiosperms. McGrawHill. New York.

Edwards, E.J., C.J. Stills \& M.J. Donoghue. 2007. The relevance of phylogeny to the studies of global change. Trends Ecol. Evol. 22: 243-249.

Eklund, H., J.A. Doyle \& P.S. Herendeen. 2004. Morphological phylogenetic analysis of living and fossil Chloranthaceae. Int. F. Plant Sci. 165: 107-151.

Endress, P.K. 2001. The flowers in extant basal angiosperms and inferences on ancestral flowers. Int. 7. Plant Sci. 162: 1111-1140.

Endress, P.K. 2008. Perianth biology in the basalmost extant angiosperms. Int. F. Plant Sci. In press.

Farrell, B.D. 1998. "Inordinate fondness" explained: why are there so many beetles? Science 281: 555.

Feduccia, A. 2003. "Big bang" for tertiary birds? Trends Ecol. Evol. 18: 172-176.

Feild, T.S., N.C. Arens, J.A. Doyle, et al. 2004. Dark and disturbed: a new image of early angiosperm ecology. Paleobiology 30: 82-107.

Feild, T.S., P.J. Franks \& T.L. Sage. 2003. Ecophysiological shade adaptation in the basal angiosperm, Austrobaileya scandens (Austrobaileyaceae). Int. F. Plant Sci. 164: 313-324.

Feild, T.S., M.A. Zwieniecki, T. Brodribb, et al. 2000. 
Structure and function of tracheary elements in $\mathrm{Am}$ borella trichopoda. Int. 7. Plant Sci. 161: 705-712.

Friedman, W.E. 1994. The evolution of embryogeny in seed plants and the developmental origin and early history of endosperm. Am. F. Bot. 81: 1468-1486.

Friis, E.M. 1997. Fossil history of magnoliid angiosperm. In: K. Iwatsuki \& P.H. Raven, Eds. pp. 121-156. Evolution and Diversification of Land Plants. Springer. New York.

Friis, E.M., P.R. Crane \& K.R. Pedersen. 1999. Early angiosperm diversification: the diversity of pollen associated with angiosperm reproductive structures in Early Cretaceous floras from Portugal. Ann. Missouri Bot. Garden 86: 259-296.

Friis, E.M., J.A. Doyle, P.K. Endress \& Q. Leng. 2003. Archaefructus - angiosperm precursor or specialized early angiosperm? Trends Plant Sci. 8: 369-373.

Friis, E.M., K.R. Pedersen \& P.R. Crane. 1994. Angiosperm floral structures from the Early Cretaceous of Portugal. Plant Syst. Evol. 8: 31-49.

Friis, E.M., K.R. Pedersen \& P.R. Crane. 2000. Reproductive structure and organization of basal angiosperms from the early Cretaceous (Barremian or Aptian) of western Portugal. Int. f. Plant Sci. 161: 5169-5182.

Friis, E.M., K.R. Pedersen \& P.R. Crane. 2001. Fossil evidence of water lilies (Nymphaeales) in the Early Cretaceous. Nature 410: 357-360.

Friis, E.M., K.R. Pedersen \& P.R. Crane. 2006. Cretaceous angiosperm flowers: innovation and evolution in plant reproduction. Paleogeogr. Paleoclimatol. Paleoecol. 232: 251-293.

Friis, E.M., P.R. Crane, K.R. Pedersen, et al. 2007. Phasecontrast X-ray microtomography links Cretaceous seeds with Gnetales and Bennettitales. Nature 450: 549-552.

Frohlich, M.W. 1999. MADS about Gnetales. Proc. Natl. Acad. Sci. USA 96: 8811-8813.

Frohlich, M.W. 2006. Recent developments regarding the evolutionary origin of flowers. In Advances in Botanical Research, vol. 44. D.E. Soltis, J.H. Leebens-Mack \& P.S. Soltis, Eds.: 64-116. Elsevier. London.

Frumin, S. \& E.M. Friis. 1999. Magnoliid reproductive organs from the Cenomanian-Turonian of northwestern Kazakhstan: Magnoliaceae and Illiciaceae. Plant Syst. Evol. 216: 265-288.

Gandolfo, M.A., K.C. Nixon \& W.L. Crepet. 2004. Cretaceous flowers of Nymphaeaceae and implications for complex insect entrapment pollination mechanisms in early angiosperms. Proc. Natl. Acad. Sci. USA 101: 8056-8060.

Graham, S.W. \& R.G. Olmstead. 2000. Utility of 17 chloroplast genes for inferring the phylogeny of the basal angiosperms. Am. f. Botany 87: 17121730
Graham, S.W., P.A. Reeves, A.C.E. Burns, et al. 2000. Microstructural changes in noncoding chloroplast DNA: interpretation, evolution, and utility of indels and inversions in basal langiosperm phylogenetic inference. Int. J. Plant Sci. 161: S83-S96.

Grant, V. 1981. Plant Speciation. Columbia University Press. New York.

Hilu, K.W., T. Borsch, K. Muller, et al. 2003. Inference of angiosperm phylogeny based on matK sequence information. Am. F. Bot. 90: 1758-1776.

Irish, V. 2006. Duplication, diversification, and comparative genetics of angiosperm MADS-box genes. In Advances in Botanical Research, vol. 44. D.E. Soltis, P.S. Soltis \& J. Leebens-Mack, Eds.: 130-151. Elsevier. New York.

Jaillon, C.O., J.-M. Aury, B. Noel, et al. 2007. The grapevine genome sequence suggests ancestral hexaploidization in major angiosperm phyla. Nature 449: 463-467.

Jansen, R.K., Z. Cai, L.A. Raubeson, et al. 2007. Analysis of 81 genes from 64 chloroplast genomes resolves relationships in angiosperms and identifies genomescale evolutionary patterns. Proc. Natl. Acad. Sci. USA 104: 19369-19374.

Jian, S., P.S. Soltis, M. Gitzendanner, et al. 2008. Resolving an ancient, rapid radiation in Saxifragales. Syst. Biol. 58: $38-57$.

Judd, W.S. \& R.G. Olmstead. 2004. A survey of tricolpate (eudicot) phylogeny. Am. F. Bot. 91: 1627-1644.

Kanno, A., H. Saeki, T. Kameya, et al. 2003. Heterotropic expression of class B floral homeotic genes supports a modified ABC model for tulip (Tulipa gesneriana). Plant Mol. Biol. 52: 831-841.

Keck E., P. McSteen, R. Carpenter, et al. 2003. Separation of genetic functions controlling organ identity in flowers. EMBO f. 22: 1058-1066.

Kim S., V.A. Albert, M.-J. Yoo, et al. 2004. Pre-angiosperm duplication of floral genes and regulatory tinkering at the base of angiosperms. Am. F. Bot. 91: 21022118.

Kim S., J. Koh, M.-J. Yoo, et al. 2005. Expression of floral MADS-box genes in basal angiosperms: implications on evolution of floral regulators and the perianth. Plant 7. 43: 724-744.

Klaus, F. \& M.M. Miyamoto. 1991 Rapid cladogenesis among the pecoran ruminants: evidence from mitochondrial DNA sequences. Syst. Zool. 40: $117-$ 130.

Kramer, E.M., V.S. Di Stilio \& P. Schluter. 2003. Complex patterns of gene duplication in the APETALA3 and PISTILLTA lineages of the Ranunculaceae. Int. $\mathcal{F}$. Plant Sci. 164: 1-11.

Kramer, E.M. R.L. Dorit \& V.F. Irish. 1998. Molecular evolution of genes controlling petal and stamen development: Duplication and divergence within the 
APETALA3 and PISTILLATA MADS-box gene lineages. Genetics 149: 765-783.

Kramer, E.M. \& V.F. Irish. 2000. Evolution of the petal and stamen developmental programs: evidence from comparative studies of the lower eudicots and basal angiosperms. Int. F. Plant Sci. 161: S29-S40.

Kramer, E.M., M.A. Jaramillo \& V.S. Di Stilio. 2004. Patterns of gene duplication and functional evolution during the diversification of the AMAMOUS subfamily of MADS-box genes in angiosperms. Genetics 166: $1011-1023$.

Kramer E. M. \& E.A. Zimmer. 2006. Gene duplication and floral developmental genetics of basal eudicots. In Advances in Botanical Research, vol. 44. D.E. Soltis, P.S. Soltis \& J. Leebens-Mack, Eds.: 354-376. Elsevier. New York.

Laura, M. J.H. Zahn, J.M. Arrington, et al. 2006. Conservation and divergence in the AMAMOUS subfamily of MADS-box genes: evidence of independent suband neofunctional events. Evol. Dev. 8: 30-45.

Leebens-Mack, J., L.A. Raubeson, L. Cui, et al. 2005. Identifying the basal angiosperm node in chloroplast genome phylogenies: sampling one's way out of the Felsenstein zone. Mol. Biol. Evol. 22: 1948-1963.

Les, D., H.E.L. Schneider, D.J. Padgett, et al. 1999. Phylogeny, classification and floral evolution of water lilies (Nymphaeaceae; Nymphaeales): a synthesis of non-molecular, $r b c L$, matK, and $18 \mathrm{~S}$ rDNA data. Syst. Bot. 24: 28-46.

Litt A. \& V.F. Irish. 2003. Duplication and diversification in the APETALA1 / FRUITFULL floral homeotic gene lineage: implications for the evolution of floral development. Genetics 165: 821-833.

Luo, J., N. Yoshikawa, M.C. Hodosn \& B.D. Hall. 2007. Duplication and paralog sorting of RPB2 and RPB1 genes in core eudicots. Mol. Phylogenet. Evol. 44: 850862.

Ma, H. \& C.W. dePamphilis. 2000. The ABCs of floral evolution. Cell 101: 5-8.

Macer, S., S. De Bodt, J. Racs, et al. 2005. Modeling gene and genome duplications in eukaryotes. Proc. Natl. Acad. Sci. USA 102: 5454-5459.

Magallón, S. \& M.J. Sanderson. 2002. Relationships among seed plants inferred from highly conserved genes: sorting conflicting phylogenetic signals among ancient lineages. Am. J. Bot. 89: 1991-2006.

Magallón, S. \& M.J. Sandersón. 2005. Angiosperm divergence times: the effects of genes, codon positions, and time constraints. Evolution 59: 1653-1670.

Martin, W., A. Gierl \& H. Saedler. 1989. Molecular evidence for pre-Cretaceous angiosperm origins. Nature 339: $46-48$.

Mathews, S. \& M.J. Donoghue. 1999. The root of angiosperm phylogeny inferred from duplicate phytochrome genes. Science 286: 947-950.
Mathews, S. \& M.J. Donoghue. 2000. Basal angiosperm phylogeny inferred from duplicate phytochromes A and C. Int. F. Plant Sci. 161: S41-S55.

Moore, M.J., C.D. Bell, P.S. Soltis, et al. 2007. Using plastid genomic-scale data to resolve enigmatic relationships among basal angiosperms. Proc. Natl. Acad. Sci. USA 104: 19363-19368.

Moore, M.J., A. Dhingra, P.S. Soltis, et al. 2006. Rapid and accurate pyrosequencing of angiosperm plastid genomes. BMC Plant Biol. 6: 17-30

Moreau, C.S., C.D. Bell, R. Vila, et al. 2006. Phylogeny of the ants: diversification in the age of angiosperms. Science 312: 101-104.

Morris, A.B., C.D. Bell, W.S. Judd, et al. 2007. Phylogeny and divergence time estimates for Illicium. Syst. Bot. 32: 36-249.

Muntzing, A. 1936. The evolutionary significance of autopolyploidy. Hereditas 21: 263-378.

Novacek, M.J. 1999. 100 million years of land vertebrate evolution: the Cretaceous-early Tertiary transition. Ann. Missouri Bot. Garden 86: 230-258.

Park, J.-M., S. Kovaić, Z. Liber, et al. 2006. Phylogeny and biogeography of isophyllous species of Campanula (Campanulaceae) in the Mediterranean area. Syst. Bot. 31: 862-880.

Parkinson, C.L., K.L. Adams \& J.D. Palmer. 1999. Multigene analyses identify the three earliest lineages of extant flowering plants. Curr. Biol. 9: 1485-1488.

Paterson, A.H., J.E. Bowers \& B.A. Chapman. 2004. Ancient polyploidization predating divergence of the cereals, and its consequences for comparative genomics. Proc. Natl. Acad. Sci. USA 101: 99039908.

Pelaz S., G.S. Ditta, E. Baumann, et al. 2000. B and C floral organ identity functions require SEPALLATA MADS-box genes. Nature 405: 200-203.

Qiu, Y., O. Dombrovska, J Lee, et al. 2005. Phylogenetic analysis of basal angiosperms based on nine plastid, mitochrondrial, and nuclear genes. Int. F. Plant Sci. 166: $815-842$.

Qiu, Y-L.,J. Lee, F. Bernasconi-Quadroni, et al. 1999. The earliest angiosperms: evidence from mitochondrial, plastid, and nuclear genomes. Nature 402: 404-407.

Qiu, Y-L., J. Lee, F. Bernasconi-Quadroni, et al. 2000. Phylogenetic analyses of basal angiosperms based on five genes from all three genomes. Int. 7. Plant Sci. 161: S3-S27.

Rijpkema A., T. Gerats \& M. Vandenbussche. 2006. Genetics of floral development in Petunia. In Advances in Botanical Research, vol. 44. D.E. Soltis, P.S. Soltis \& J. Leebens-Mack, Eds.: 237-270. Elsevier. New York.

Ramshaw, J.A.M., D.L. Richardson, B.T. Meatyard, et al. 1972. The time of origin of the flowering plants determined by using amino acid sequence data of cytochrome C. New Phytologist 71: 773-779. 
Roelants, K., D.J. Gower, M. Wilkinson, et al. 2007. Global patterns of diversification in the history of modern amphibians. Proc. Natl. Acad. Sci. USA 104: 887-892.

Rudall, P.J., D.D. Sokoloff, M.V. Remizowa, et al. 2007. Morphology of Hydatellaceae, an anomalous aquatic family recently recognized as an earlydivergent angiosperm lineage. Am. F. Bot. 94: 10731092.

Saarela, J.M., H.S. Rai, J.A. Doyle, et al. 2007. Hydatellaceae identified as a new branch near the base of the angiosperm phylogenetic tree. Nature 446: 312-315.

Sanderson, M.J. 1997. A nonparametric approach to estimating divergence times in the absence of rate constancy. Mol. Biol. Evol. 14: 1218-1231.

Sanderson, M.J. \& J.A. Doyle. 2001. Sources of error and confidence intervals in estimating the age of angiosperms from $r b c L$ and $18 \mathrm{~S}$ rDNA data. $A m \mathcal{F}$. Botany 88: 1499-1516.

Sanderson, M.J., J.L. Throne, N. Wikström, et al. 2004. Molecular evidence on plant divergence times. $\mathrm{Am}$. 7. Botany 91: 1656-1665.

Schneider, H., E. Schuettpelz, K.M. Pryer, et al. 2004. Ferns diversified in the shadow of angiosperms. $\mathrm{Na}$ ture 428: 553-557.

Schwarz-Sommer, Z., P. Huijser, W. Nacken, et al. 1990. Genetic control of flower development by homeotic genes in Antirrhinum majus. Science 250: 931-936.

Slingsby, J.A. \& G.A. Verboom. 2006. Phylogenetic relatedness limits co-occurrence at fine spatial scales: evidence from the schoenoid sedges (Cyperaceae: Schoeneae) of the Cape Floristic Region, South Africa. Am. Nat. 168: 14-27.

Soltis, D.E., V.A. Albert, J. Leebens-Mack, et al. 2008. The Amborella genome: an evolutionary reference for plant biology. Genome Biol., 9: 402.

Soltis, D.E., V.A. Albert, V. Savolainen, et al. 2004. Genomic-scale data, angiosperm relationships, and "ending incongruence": a cautionary tale in phylogenetics. Trends Plant Sci. 9: 477-483.

Soltis, D.E., A. Chanderbali, S. Kim, et al. 2007b. The ABC Model and its applicability to basal angiosperms. Ann. Bot. 100: 155-163.

Soltis, D.E., M. Gitzendanner \& P.S. Soltis. 2007a. A Bayesian analysis of the three-gene, 567-taxon data set for angiosperms. Int. F. Plant Sci. 168: 137-157.

Soltis, D.E. \& P.S. Soltis. 1990. Isozyme evidence for ancient polyploidy in primitive angiosperms. Syst. Bot. 15: 328-337.

Soltis, D.E. \& P.S. Soltis. 1999. Polyploidy: recurrent formation and genome evolution. Trends Ecol. Evol. 14: 348-352.

Soltis, D.E., P.S. Soltis, V.A. Albert, et al. 2002. Missing links: the genetic architecture of the flower and floral diversification. Trends Plant Sci. 7: 22-30.
Soltis, D.E., P.S. Soltis, P.K. Endress, et al. 2005. Phylogeny and Evolution of the Angiosperms. Sinauer. Sunderland, MA.

Soltis, P.S. \& D.E. Soltis. 2004. Phylogeny and evolution of the angiosperms. Am. F. Botany 91: 1614-1626.

Soltis, D.E., P.S. Soltis, M.W. Chase, et al. 2000. Angiosperm phylogeny inferred from a combined data set of $18 \mathrm{~S}$ rDNA, $r b c L$, and $a t p B$ sequences. Bot. $\mathcal{F}$. Linnean Soc. 133: 381-461.

Soltis, P.S., S. Kim, M. Buzgo \& D.E. Soltis. 2006. Expression of floral regulators in basal angiosperms and the origin and evolution of the ABC model. Dev. Genetics Flower Adv. Botan. Res. 44: 484-502.

Soltis, P.S., D.E. Soltis \& M.W. Chase. 1999b. Angiosperm phylogeny inferred from multiple genes: a research tool for comparative biology. Nature 402: 402404.

Soltis, P.S., D.E. Soltis, P.G. Wolf, et al. 199a. The phylogeny of land plants inferred from 18S rDNA sequences: Pushing the limits of rDNA signal? Mol. Biol. Evol. 16: 1774-1784.

Stebbins, G.L. 1950. Variation and Evolution in Plants. Columbia University Press. New York.

Stefanović, S., D.W. Rice \& J.D. Palmer. 2004. Long branch attraction, taxon sampling, and the earliest angiosperms: Amborella or monocots? Evol. Biol. 4: 35.

Sun, G., Q. Li, D.L. Dilcher, et al. 2002. Archaefructaceae, a new basal angiosperm family. Science 296: 899904.

Takhtajan, A. 1991. Evolutionary Trends in Flowering Plants. Columbia University Press. New York.

Teeri, T., M. Kotilainen, A. Uimari, et al. 2006. Floral developmental genetics of Gerbera. In $A d-$ vances in Botanical Research, vol. 44. D.E. Soltis, P.S. Soltis \& J. Leebens-Mack, Eds.: 323-347. Elsevier. New York.

Theissen, G., A. Becker, A. Di Rosa, et al. 2000. A short history of MADS-box genes in plants. Plant Mol. Biol. 42: 115-149.

Tuskan, G.A., S. DiFazio, S. Jansson, et al. 2006. The genome of Black Cottonwood, Populus trichocarpa (Torr. \& Gray). Science 313: 1594-1604.

Upchurch, G.R. \& J.A. Wolfe 1993. Cretaceous vegetation of the western Interior and adjacent regions of North America. In Evolution of the Western Interior Basin, vol. 39. W.G.E. Caldwell \& E.G. Kauffman, Eds.: 243-281. Geological Association of Canada Special Paper.

Vamosi J.C., T.M. Knight, J.A. Steets, et al. 2006. Pollination decays in biodiversity hotspots. Proc. Natl. Acad. Sci. USA 103: 956-961.

Velasco, R., A. Zharkikh, M. Troggio, et al. 2007. A high quality draft consensus sequence of the genome of a heterozygous grapevine variety. PLoS ONE 2: e1326. 
Vision, T.J., D.G. Brown \& S.D. Tanksley. 2000. The origins of genomic duplications in Arabidopsis. Science 290: $2114-2117$.

Wall, P.K., J. Leebens-Mack, A. Barakat, et al. 2007. Next-generation transcriptome sequencing. Submitted.

Wang, H. M.. J. Moore, P.S. Soltis, et al. 2008. Rosid diversification and the rapid rise of angiosperm domonated forests. Proc. Nat. Acad. Sci. Submitted.

Webb, C.O., D.D. Ackerly \& S.W. Kembel. 2007. Phylocom: software for the analysis of community phylogenetic structure and trait evolution. Version 3.41. http://www.phylodiversity.net/phylocom/.

Wible, J.R., G.W. Rougier, M.J. Novacek, et al. 2007. Cretaceous eutherians and Laurasian origin for placental mammals near the K/T boundary. Nature 447: 1003-1006.

Wilf, P., C.C. Labandeira, W. John Kress, et al. 2000. Timing the radiations of leaf bettles: hispines on gingers from the Latest Cretaceous to Recent. Science 289: 291-294.
Wikström, N., V. Savolainen \& M.W. Chase. 2001. Evolution of the angiosperms: calibrating the family tree. Proc. R. Soc. Lond. B Biol. Sci. 268: 22112220.

Yoo, M.J., C.D. Bell, P.S. Soltis, et al. 2005. Divergence times and historical biogeography of Nymphaeales. Syst. Bot. 30: 693-704.

Zahn L.M., H. Kong, J.H. Leebens-Mack, et al. 2005. The evolution of the SEPALLATA subfamily of MADSbox genes: a pre-angiosperm origin with multiple duplications throughout angiosperm history. Genetics 169: 2209-2223.

Zanis M.J., D.E. Soltis, P.S. Soltis, et al. 2002. The root of the angiosperms revisited. Proc. Natl. Acad. Sci. USA 99: 6848-6853.

Zanis, M.J., D.E. Soltis, P.S. Soltis, et al. 2003. Phylogenetic analyses and perianth evolution in basal angiosperms. Ann. Missouri Bot. Garden 90: 129-150.

Zhang, L.B. \& S. Renner. 2003. The deepest splits in Chloranthaceae as resolved by chloroplast sequences. Int. f. Plant Sci. 164: S383-S392. 